We thank Drs Tanaka S, Haga N, Yukioka M, Hashimoto J, Miyahara H, Niki Y, Kimura $\mathrm{T}$, Oda $\mathrm{H}$, Funahashi $\mathrm{K}$ for their contribution to this study and all medical staff members of each institute for their data collection efforts for their data collection efforts.

Disclosure of Interests: Toshihisa Kojima Grant/research support from: Chugai, Eli Lilly, Astellas, Abbvie, and Novartis, Consultant of: AbbVie, Speakers bureau: AbbVie, Astellas, Bristol-Myers Squibb, Chugai, Daiichi-Sankyo, Eli Lilly, Janssen, Mitsubishi Tanabe, Pfizer, and Takeda, Masayo Kojima: None declared, Hajime Ishikawa: None declared, Keiichiro Nishida Grant/ research support from: K. Nishida has received scholarship donation from CHUGAI PHARMACEUTICAL Co., Eisai Co., Mitsubishi Tanabe Pharma and AbbVie GK., Speakers bureau: K. Nishida has received speaking fees from CHUGAI PHARMACEUTICAL Co., Eli Lilly, Janssen Pharmaceutical K.K., Eisai Co. and AYUMI Pharmaceutical Corporation., Shuji Asai Speakers bureau: AbbVie, Astellas, Bristol-Myers Squibb, Chugai, Daiichi-Sankyo, Eisai, Janssen, Takeda, and UCB Japan, Naoki Ishiguro Grant/research support from: AbbVie, Asahi Kasei, Astellas, Chugai, Daiichi-Sankyo, Eisai, Kaken, Mitsubishi Tanabe, Otsuka, Pfizer, Takeda, and Zimmer Biomet, Consultant of: Ono, Speakers bureau: Astellas, Bristol-Myers Squibb, Daiichi-Sankyo, Eli Lilly, Pfizer, and Taisho Toyama

DOI: 10.1136/annrheumdis-2020-eular.4218

\section{AB1173 RHEUMATOLOGIST CARE IS ASSOCIATED WITH FEWER EMERGENCY ROOM VISITS BY PERSONS WITH GOUT}

N. Schlesinger ${ }^{1}$, N. L. Edwards ${ }^{2}$, S. Clark ${ }^{3}$, P. Lipsky ${ }^{4} .{ }^{1}$ Rutgers Robert Wood Johnson Medical School, Division of Rheumatology, Department of Medicine, New Brunswick, United States of America; ${ }^{2}$ University of Florida, Department of Medicine, Gainesville, United States of America; ${ }^{3} \mathrm{HVH}$ Precision Analytics, Wayne, United States of America; ${ }^{4}$ RILITE Research Institute, Charlottesville, United States of America

Background: Gout is one of the most common inflammatory arthropathies. By searching a large administrative data base (Symphony Integrated Dataverse), we found that persons with acute gout see a rheumatologist infrequently, whereas less than $50 \%$ of advanced gout patients are seen by a rheumatologist. Notably, however, gout patients seen by rheumatologists have more frequent urate measurements and are prescribed urate lowering therapy more frequently. This study sought to determine whether involvement of a rheumatologist in gout care had a positive impact on health outcomes

Objectives: To determine whether involvement of a rheumatologist had a positive impact on health outcomes of patients with gout.

Methods: We carried out a retrospective analysis to identify persons with gout over an approximately 3-year period from October 2015 to December 2018. This study used data from the Truven Marketscan ${ }^{\circledR}$ database, an administrative database covering over 190 million patients across the United States and based on fully adjudicated and paid insurance claims. Patients were identified as having gout if they were $>18$ years of age and had at least two medical claims for the diagnosis of gout on different days, separated by at least 3 months. Patients with acute gout were identified by ICD-10 code M10.*, chronic nontophaceous gout (M1A. $\left.{ }^{* \star *} 0\right)$, tophaceous gout $\left(\mathrm{M} 1 \mathrm{~A} .{ }^{* \star *} 1\right)$ and uncontrolled gout $\left(\mathrm{M} 10 .^{*}, \mathrm{M} 1 \mathrm{~A} .{ }^{*}\right)$, the latter manifested by three gout codes (any) in the primary diagnosis position and three urate measurements within the same calendar year. Particular attention was placed on Emergency Room (ER) visits by individuals in each category and by individuals who had been evaluated by a rheumatologist. Results: We identified 284,877 gout patients. The median age was 59.2 years and $79.0 \%$ were male. Of the 230,998 persons coded as acute gout, $10.7 \%$ were seen by a rheumatologist, whereas $26.9 \%$ of the 32,942 coded as chronic nontophaceous gout, $47.2 \%$ of the 7,723 coded as tophaceous gout and $43.6 \%$ of the 13,514 coded as uncontrolled gout were seen by a rheumatologist. In each gout category, the frequency of ER visits was significantly reduced in persons who had been seen by a rheumatologist (Table 1). In acute gout, the frequencies of ER visits in those with and without rheumatologist care were $5.6 \%$ vs $6.6 \%(p<0.001)$, respectively. In chronic nontophaceous gout it was $5.5 \%$ vs $6.7 \%$ ( $p=0.001)$; in tophaceous gout it was $10.3 \%$ vs $14.7 \%$ $(\mathrm{p}<0.001)$; and in uncontrolled gout it was $12.8 \%$ vs $19.0 \%$, respectively. If the frequencies of rheumatologist-associated gout patient ER visits were applied to all gout subjects, there would have been 3,088 less ER visits in this cohort of gout patients.
Table 1.

\begin{tabular}{|c|c|c|c|c|c|c|c|}
\hline \multirow[b]{2}{*}{ Population } & \multirow[b]{2}{*}{ Overall N } & \multicolumn{3}{|c|}{ Rheumatology Breakdown } & \multicolumn{3}{|c|}{ Emergency Room Visits } \\
\hline & & $\begin{array}{c}\text { W/ } \\
\text { Rheumatology }\end{array}$ & Patients & $\%$ & $\begin{array}{c}\text { With Gout } \\
\text { ER Visit (\%) }\end{array}$ & $\begin{array}{c}\text { p-value } \\
\text { (compar- } \\
\text { ing \%) }\end{array}$ & $\begin{array}{c}\text { ER } \\
\text { Visits* } \\
\text { Per } \\
\text { Patient }\end{array}$ \\
\hline Acute Gout & 230,698 & $\begin{array}{l}\text { Yes } \\
\text { No }\end{array}$ & $\begin{array}{c}24,638 \\
206,060\end{array}$ & $\begin{array}{l}10.68 \% \\
89.32 \%\end{array}$ & $\begin{array}{c}1373(5.57 \%) \\
13632 \\
(6.62 \%)\end{array}$ & $<0.001$ & $\begin{array}{l}1.47 \\
1.53\end{array}$ \\
\hline $\begin{array}{l}\text { Non- } \\
\text { Tophaceous } \\
\text { Chronic }\end{array}$ & 32,942 & $\begin{array}{l}\text { Yes } \\
\text { No }\end{array}$ & $\begin{array}{c}8,863 \\
24,079\end{array}$ & $\begin{array}{l}26.90 \% \\
73.10 \%\end{array}$ & $\begin{array}{c}486(5.48 \%) \\
1601(6.65 \%)\end{array}$ & $<0.001$ & $\begin{array}{l}1.95 \\
2.39\end{array}$ \\
\hline $\begin{array}{c}\text { Tophaceous } \\
\text { Chronic }\end{array}$ & 7,723 & $\begin{array}{l}\text { Yes } \\
\text { No }\end{array}$ & $\begin{array}{l}3,648 \\
4,075\end{array}$ & $\begin{array}{l}47.24 \% \\
52.76 \%\end{array}$ & $\begin{array}{l}376(10.31 \%) \\
597(14.65 \%)\end{array}$ & $<0.001$ & $\begin{array}{l}2.78 \\
2.89\end{array}$ \\
\hline Uncontrolled & 13,514 & $\begin{array}{l}\text { Yes } \\
\text { No }\end{array}$ & $\begin{array}{l}5,886 \\
7,628\end{array}$ & $\begin{array}{l}43.55 \% \\
56.45 \%\end{array}$ & $\begin{array}{c}753(12.79 \%) \\
1452 \\
(19.04 \%)\end{array}$ & $<0.001$ & $\begin{array}{l}2.06 \\
2.56\end{array}$ \\
\hline
\end{tabular}

* ER Visits are only included in this analysis if the primary diagnosis code on the claim is a gout code (M10.X, M1A.X)

Conclusion: There appears to be a positive impact of rheumatologist involvement in the care of gout patients, manifested by a significant decrease in the frequency of ER visits. Considering the inconvenience and cost of ER visits, rheumatologist care may have a significant impact on the well-being of gout patients and on the overall cost of their care.

Disclosure of Interests: Naomi Schlesinger Grant/research support from: Pfizer, Amgen, Consultant of: Novartis, Horizon Therapeutics, Selecta Biosciences, Olatec, IFM Therapeutics, Mallinckrodt Pharmaceuticals, N. Lawrence Edwards Consultant of: Horizon Therapeutics, Takeda Pharmaceuticals US, Aclaris Therapeutics, Atom Biosciences, Sanders Clark: None declared, Peter Lipsky Consultant of: Horizon Therapeutics DOI: 10.1136/annrheumdis-2020-eular.2340

\section{AB1174 TRACKING THE EFFECTS ON A CLINICAL SERVICE OF INTRODUCING ULTRASOUND FOR DIAGNOSIS OF GIANT CELL ARTERITIS: DESIGN OF A SERVICE EVALUATION USING LEAN METHODOLOGY}

S. Mackie $^{1,2}$, A. Barr ${ }^{3}$, A. Cracknell ${ }^{4}$, S. Farrell ${ }^{3}$, J. Parvin ${ }^{5}$, A. Patil ${ }^{6}$, I. Simmons ${ }^{6}$, K. Smith ${ }^{3}$, A. Sweeting ${ }^{3}$, M. Troxler ${ }^{7}$, T. Webster $^{7}$, R. Wakefield ${ }^{1,2}$. ${ }^{1}$ University of Leeds, Leeds Institute of Rheumatic and Musculoskeletal Medicine, Leeds, United Kingdom; ${ }^{2}$ Leeds Teaching Hospitals NHS Trust, NIHR Leeds Biomedical Research Centre, Leeds, United Kingdom; ${ }^{3}$ Leeds Teaching Hospitals NHS Trust, Rheumatology, Leeds, United Kingdom; ${ }^{4}$ Leeds Teaching Hospitals NHS Trust, Geriatric Medicine, Leeds, United Kingdom; ${ }^{5}$ Leeds Teaching Hospitals NHS Trust, Kaizen Promotion Office, Leeds, United Kingdom; ${ }^{6}$ Leeds Teaching Hospitals NHS Trust, Ophthalmology, Leeds, United Kingdom; ${ }^{7}$ Leeds Teaching Hospitals NHS Trust, Vascular Surgery, Leeds, United Kingdom

Background: In our large, multi-site hospital, patients with suspected GCA are started promptly on high-dose prednisolone but until 2019, patients waited for temporal artery biopsy (TAB) until the GCA diagnosis could be confirmed ("GCA") or refuted ("not-GCA"). Reports of the impact of introducing temporal and axillary artery ultrasound (TAUS) have mainly come from smaller hospitals. Agreement between TAUS and TAB has been reported by others with a Cohen's kappa of 0.35 [1] and 0.40 [2]. We used Lean methodology to identify metrics across 5 key domains: delivery, quality, service, morale and cost.

Objectives: To design metrics for a service evaluation to measure impact of introducing TAUS, and to test their feasibility of measurement within routine care. Methods: Our primary driver was time from presenting to our service to diagnostic confirmation (lead time). Pathway mapping, value stream mapping and a driver diagram identified key ideas for improvement.

We chose to measure: Delivery (mean lead time for each month), Quality (proportion of patients with GCA and positive TAB/TAUS; total (cumulative) prednisolone dose in patients with not-GCA, Service (patient feedback), Morale (staff feedback) and Cost (number of patients; cost of tests per patient; overall costs). We plotted these by month on run charts and defined a significant shift as 6 consecutive monthly values below baseline median. Cohen's kappa was calculated using GraphPad QuickCalcs.

Results: Routine TAUS for suspected GCA was introduced from January 2019, alongside a multidisciplinary team monthly meeting. TAUS was done a median 